\title{
Development of a lightweight, 'on-bed', portable isolation hood to limit the spread of aerosolized influenza and other pathogens
}

\author{
Hidekazu Nishimura ${ }^{1}$, Soichiro Sakata ${ }^{2}$ \\ ${ }^{1}$ Virus Research Center, Clinical Research Division, Sendai Medical Center, National Hospital Organization, Sendai, Japan; ${ }^{2}$ Mediair Japan Inc., \\ Yokohama, Japan \\ Contributions: (I) Conception and design: All authors; (II) Administrative support: H Nishimura; (III) Provision of study materials or patients: All \\ authors; (IV) Collection and assembly of data: All authors; (V) Data analysis and interpretation: All authors; (VI) Manuscript writing: All authors; (VII) \\ Final approval of manuscript: All authors. \\ Correspondence to: Hidekazu Nishimura. Virus Research Center, Clinical Research Division, Sendai Medical Center, National Hospital Organization, \\ 2-11-12 Miyagino, Miyagino, Sendai 983-8520, Japan. Email: hide-nishimura@mte.biglobe.ne.jp.
}

Background: The annual seasonal influenza epidemics in the winter season lead to many hospital admissions, increasing risks of nosocomial infections. Infectious diseases caused by contagious respiratory pathogens also pose a great risk to hospitals as has been seen in the current epidemic by a novel coronavirus infection. Such risk occurs in high density patient settings with few or no partitions, since the pathogens are transmitted by aerosols discharged from the patients. Possible interventions against the transmission are needed.

Methods: We developed a compact, lightweight, and portable hood designed to cover just the top half of a patient sitting or lying in bed, to limit the dissemination of infectious aerosols, constructed out of lightweight pipes, transparent plastic curtains, and a fan-filter-unit (FFU). The containment efficacy of the product was tested using an aerosolized cultured influenza virus tracer and an optimal airflow rate was determined according to the test results. It was tested for use in hospital wards during the 2016-2018 influenza seasons.

Results: The hood, named as Barrihood ${ }^{\circledR}$, had dimensions height $172 \mathrm{~cm}$, width $97 \mathrm{~cm}$, length $38 \mathrm{~cm}$, weighed $26 \mathrm{~kg}$, and easily strolled and unfolded from its stored to its fully operational state of length $125 \mathrm{~cm}$ within a few minutes by a single operator. Optimal operational airflow-rate of the FFU was $420 \mathrm{~L} / \mathrm{min}$ for containment of the aerosol particles. Eighty-one uninfected patients remained for 176 cumulative persondays within 1-4 $\mathrm{m}$ of influenza-infected patients isolated within the hood, without acquiring influenza infection.

Conclusions: With the use of the hood, secondary influenza infection cases significantly decreased, compared to previous influenza seasons. It may be suited to hospitals with not enough/no negative pressure facilities, or without enough number of individual patient isolation rooms, and could contribute to decrease the risk of nosocomial infections.

Keywords: Infection control; airborne transmission; isolation hood; containment; portability

Submitted Feb 28, 2020. Accepted for publication Jun 03, 2020.

doi: $10.21037 /$ jtd-20-1072

View this article at: http://dx.doi.org/10.21037/jtd-20-1072

\section{Introduction}

Each winter, the annual seasonal influenza epidemics lead to large numbers of hospital admissions, increasing the risk of nosocomial infections (1). In addition, emerged infectious diseases like the current novel coronavirus disease, COVID-19 also pose a great risk to safety in medical settings (2). Such nosocomial transmission risks are increased in settings where multiple patients are cared simultaneously in narrow closed areas for a long time with few or no 
effective partitions among the infected patients, noninfected patients, and medical staff, such as hospital wards (2) or renal dialysis units facilities (3), where airborne infectious agents are transmitted by breathing, coughing and sneezing (4). However, drugs for treatment or prophylaxis are only available for influenza, and not for infections with other respiratory viruses. Effective physical interventions like the isolation of the infected patient can help to reduce nosocomial transmission (5). However, few hospitals have sufficient individual patient isolation rooms availableeven fewer with negative pressure ventilation capability (6). Use of personal protective equipment (PPE) such as face masks (7), and increasing ventilation rates (i.e., airexchanges per hour, ACH) (8), with or without stand-alone room air filtration units or air-cleaners (electronic fanHEPA-filter units, FFUs) (9) are alternative ways.

However, such methodologies have their own disadvantages, e.g., face-masks need frequent changes to maintain their filtration efficacy and are uncomfortable; high ventilation rates are costly to maintain and requires more frequent, regular maintenance.

To offer an alternative containment option, we tried to develop an individual half-patient hood system. The hood has requirements: it should qualify scientific concerns such as proof of containment of the aerosol with physical particles and that with viruses inside the hood, and, in addition, compact and easily-portable for practical use in clinical settings, and at reasonable cost. We designed the hood as having a small fan-filter air-extraction system. It was tested repeatedly to get the optimized air flowrate of the fan to contain the aerosol particles from a patient inside the hood. Eventually we could succeed in developing the hood that satisfies the requirements and report its process.

\section{Methods}

\section{Ethics approval}

This study was approved by the ethics committee of Sendai National Hospital (approval No. 17-2), and conformed to the provisions of the Declaration of Helsinki (as revised in Edinburgh 2000).

\section{Patient isolation bood design}

To achieve and maintain good air containment, compactness, and portability, we designed the structure of the hood to cover just the upper half body of a patient lying on the bed, and to construct it out of FFU, plastic curtains and a metal pipe framework on wheels (Barrihood ${ }^{\circledR}$, Takasago Thermal Engineering Co., Ltd, Tokyo, Japan). The final product was light $(26 \mathrm{~kg})$ and able to be unfolded from its stored to its fully operational state within a few minutes by a single operator. Thanks to the size, weight and the wheels, it was possible to be strolled easily by a single person from a patient room to room. The front curtain was designed to drape over the legs or hips of the supine or reclining with ends of the other three curtains tucked under the mattress (Figure 1).

The location of the FFU was determined based on the data of dynamics of human cough for the most efficient filtration of the airborne bioparticles discharged from the patient lying on the bed. The FFU was integrated at a height of about $60-70 \mathrm{~cm}$ from the bed surface and the ceiling of the hood was $30 \mathrm{~cm}$ higher than the FFU because aerosols produced by human coughs have been reported to reach about $50 \mathrm{~cm}$ from the mouth and dispersed after that (10).

Experiments on the FFU set at various airflow rates from 0 to $420 \mathrm{~L} / \mathrm{min}$ were conducted for evaluation of controlling bioparticles, as well as patient thermal comfort and noise tolerance levels.

\section{Chamber for experiments using airborne influenza virus}

All experiments were conducted in a strict biosafety facility, which included frequent monitoring of the levels of airborne particles and filtering of the air using FFUs.

The double enclosure system used included an inner sealed chamber of $14.4 \mathrm{~m}^{3}(1.8 \mathrm{~m} \times 4.0 \mathrm{~m} \times 2.0 \mathrm{~m}$-high $)$ made of plastic sheet walls, equipped with FFUs to enable rapid removal of any residual airborne virus. The patient hood device was enclosed within this first sealed chamber. This first enclosure system was placed within a larger secondary clean room chamber in which a $50 \mathrm{~Pa}$ negativepressure differential to the outside ambient air was always maintained. Additional FFUs and UV lights were set around the inner, first enclosure. The temperature and relative humidity in the larger chamber were kept controlled at $21-22{ }^{\circ} \mathrm{C}$ and about $30 \%$, respectively.

\section{Virus and airborne experiments}

About $0.05 \mathrm{~mL}$ of allantoic fluid of fertilized hen's eggs, in which influenza A/Aichi/2/68 (H3N2) virus was propagated, was atomized inside the patient hood, simulating bioparticles of a patient's cough using an electric compressor- 

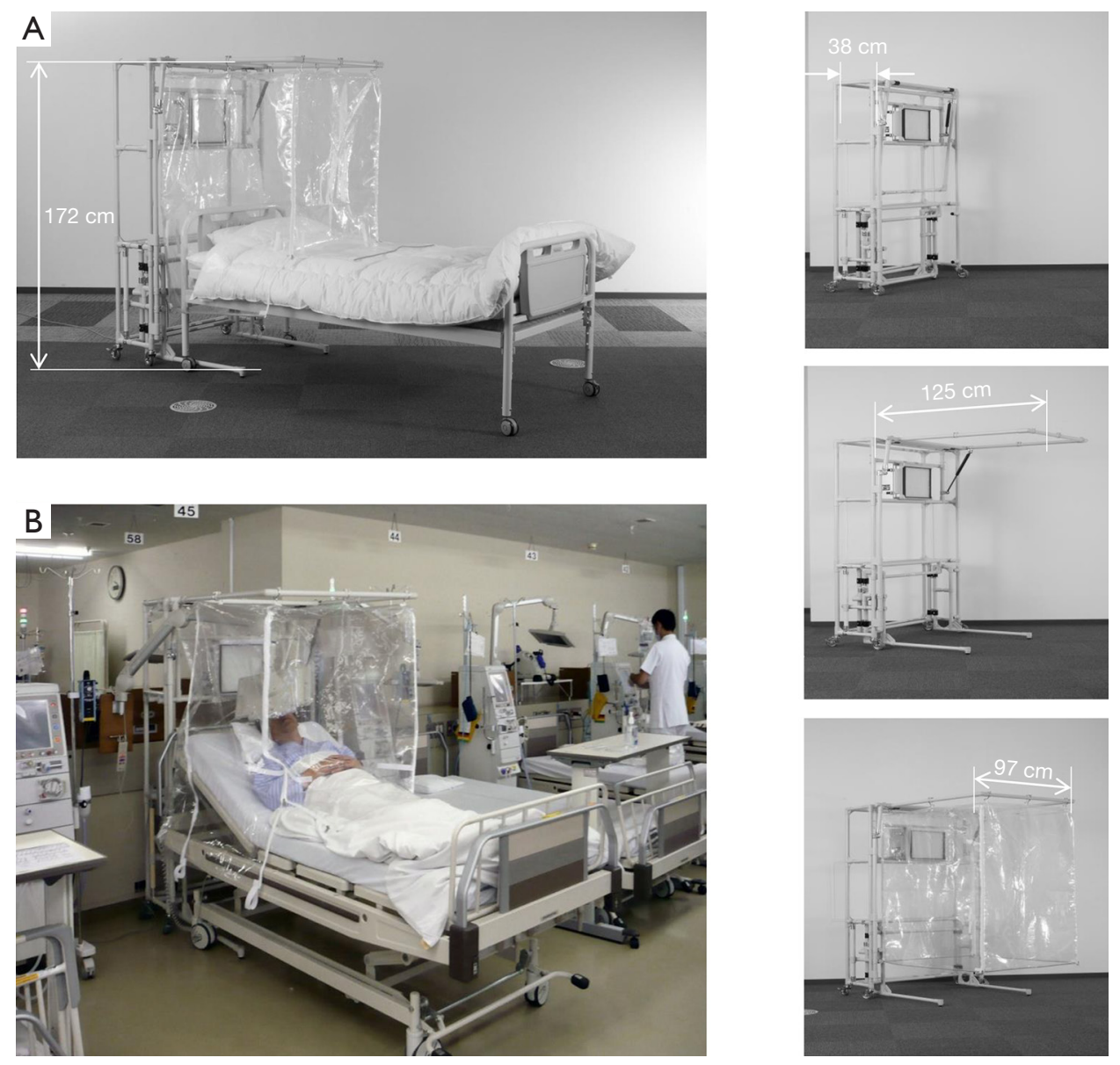

Figure 1 Features and set-up of Barrihood ${ }^{\circledR}$. (A) The dimensions of the Barrihood ${ }^{\circledR}$ and (B) its position, in situ, on a patient bed set in a renal dialysis facility.

type nebulizer, which generated mists of 1-10 $\mu \mathrm{m}$ diameter particles (NE-C16; Omron, Kyoto, Japan). Airborne particles were collected from inside and outside of the patient hood using an air sampler and a gelatin membrane filter (MD8 AirScan Sartorius AG, Göttingen, Germany) for virus detection and quantitation, as described previously (11). A total of $320 \mathrm{~L}$ of air was passed through the membrane at a flow rate of $80 \mathrm{~L} / \mathrm{min}$ (i.e., 4 minutes sampling time). The gel membrane filter was then dissolved in $10 \mathrm{~mL}$ of culture medium, Minimal Essential Medium Eagle (Sigma-Aldrich, UK), $\left(37^{\circ} \mathrm{C}\right)$ then subjected to a conventional plaque assay using Madin-Darby canine kidney (MDCK) cells (12).

\section{Use in hospital wards}

During the 2016-2017, and 2017-2018 influenza seasons, these half-patient hoods were used in the 700-bed Sendai Medical Center (Sendai City, Japan), where individual patient isolation facilities were unavailable. An influenza patient in a bed with the hood and non-influenza patient(s) stayed with a distance ranging from 1 to $4 \mathrm{~m}$ in a room. The influenza-infected patients were diagnosed using an influenza virus antigen-detection point-of-care-test kit (POCT, Immunoace Flu ${ }^{\circledR}$, Tauns, Izunokuni, Japan), when they started exhibiting influenza-like illness.

\section{Results}

\section{Optimal patient isolation hood design parameters}

An FFU airflow rate of $133 \mathrm{~L} / \mathrm{min}$ was the minimum rate which prevented leakage of airborne viruses below the assay detection limit, and rapidly cleared any airborne virus 


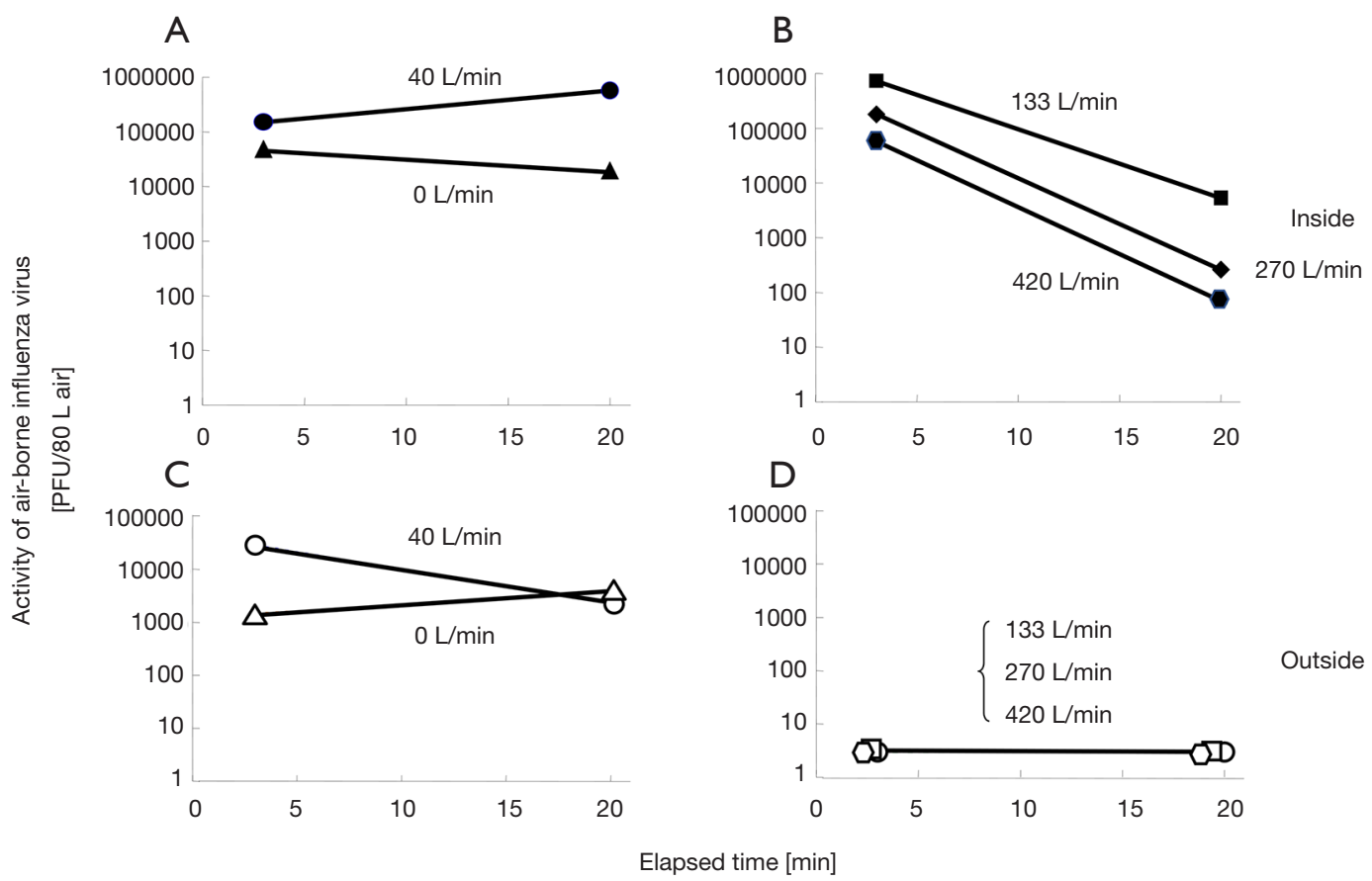

Figure 2 Aerosol containment experiments. The virus fluid was atomized in the hood in the presence of an active FFU of various air flow rates from 0 to $420 \mathrm{~L} / \mathrm{min}$. At the 0 and $20 \mathrm{~min}$ after switching on the FFU, the mists inside and outside the hood were sampled with air for 3 min, followed by titration of the viral amounts in them. The filled and empty symbols represent the amounts of active viruses in the air collected inside (A,B) and outside (C), (D) the Barrihood $^{\circledR}$, respectively.

within 20 minutes (Figure 2). However, a higher flow rate of $420 \mathrm{~L} / \mathrm{min}$ was selected to allow for a high margin of safety for practical purposes. This was required to allow for any potential flow reduction due to filter clogging (if there was a delay in maintenance), or when a larger containment air volume is accidentally created by the front curtain and the patient's body.

To test the redundancy of the system, a $10 \mathrm{~cm}$-diameter hole was created in one side of the hood to simulate a potential for leakage from the inside to the outside at different flow rates. Despite this, it was confirmed that the $420 \mathrm{~L} / \mathrm{min}$ was enough to achieve and maintain functional containment in the presence of such a gap.

This flow rate was also optimal for patients, in terms of thermal comfort and noise tolerance. After selecting this $420 \mathrm{~L} / \mathrm{min}$ flow rate, a small, quiet FFU (VFT-50-H-ATS JAPAN Vilene, Tokyo, Japan) was installed. This was a small unit $(300 \mathrm{~mm} \mathrm{~W} \times 300 \mathrm{~mm} \mathrm{~L} \times 235 \mathrm{~mm} \mathrm{D})$ with a noise level of $27 \mathrm{~dB}$ in the laboratory and up to $44 \mathrm{~dB}$ in the presence of additional background noise.

To confirm visually that the aerosol of a cough from a person inside the hood was sucked efficiently into the FFU set at the height setting designed to collect it efficiently, a trial was performed. A man coughed inside the hood after one breath of smoking while the FFU was active at an airflow rate of $420 \mathrm{~L} / \mathrm{min}$. Cough particles were substituted with tobacco smoke coughed out. The dense smoke cloud mass dispersed soon but the dispersed smoke flowed toward the FFU and was sucked into it (Figure 3).

\section{Performance of the hood during influenza seasons}

A total of 43 acute phase influenza A patients in the Barrihood stayed with a total of 81 non-influenza patients in 2-, 4-, 5- and 6-bedded rooms, in close proximity to each other for a combined, cumulative total of 176 day-persons. There occurred no new influenza infection in the rooms where the hoods were used.

\section{Discussion}

The result of actual use in wards of a hospital has limitations for interpretation since it was not an authentic case control study. However, it is worth mentioning that at the least it was 


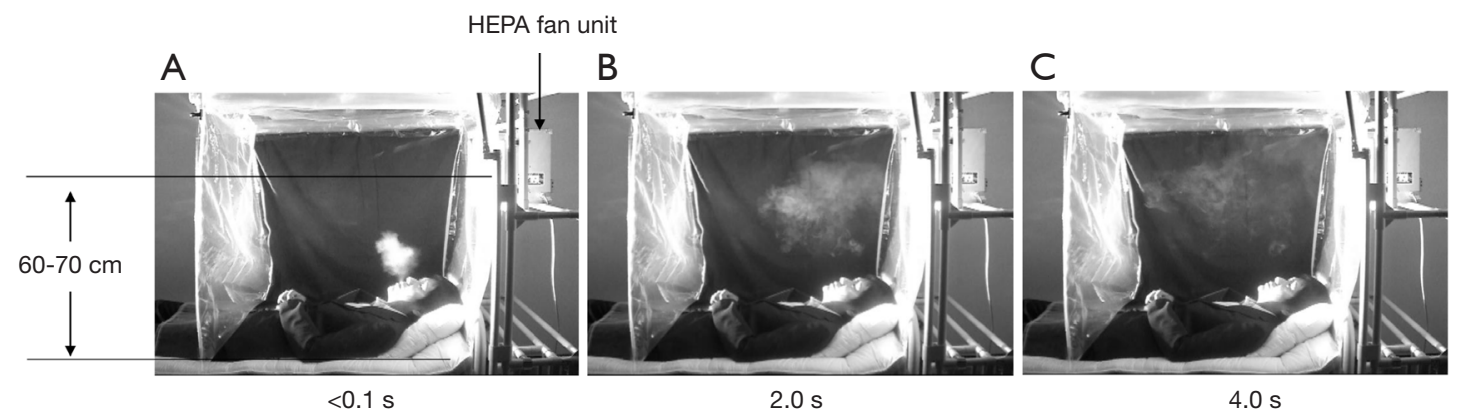

Figure 3 Dynamics of bioparticles originating from coughing in the Barrihood ${ }^{\circledR}$. A man coughed inside the hood after one breath of smoking. Cough particles are substituted with tobacco smoke coughed out. The pictures are from a digital video at (A) less than $0.1 \mathrm{~s}$, (B) $2.0 \mathrm{~s}$ and (C) $4.0 \mathrm{~s}$ after coughing. The smoke cloud dispersed but flowed toward the fan-filter unit. The airflow rate of the FFU was $420 \mathrm{~L} / \mathrm{min}$.

not proven to be of no effect. Case control studies to prove the effectiveness of the hood in medical settings are awaited.

This lightweight, portable isolation hood was designed on the basis that the risk of nosocomial infection via airborne pathogens can be reduced by controlling the number of airborne particles containing such pathogens. Although several other similar products are commercially available, these are much more costly and complex to setup, and their protective efficacy has not been demonstrated using airborne, live virus tracers. Apart from the containment efficacy, such hoods need to take into account the patient's thermal comfort and noise tolerance, as well as the impact of apparent social isolation. The appropriate FFU airflow rate setting impacts on the thermal and noise comfort levels, and a larger space within the hood together with transparent curtains, may reduce any potential feelings of claustrophobia by the patients within (Figure 1). Such space inside the hood is also required for any additional respiratory assistance devices, such as mechanical ventilation tubing, and/or for nurses to perform suctioning of sputum from the patient, etc. Video screens can also be installed within the hood for patient entertainment, if needed.

The noise of the FFU should be more improved by using FFU system with bigger fan that can reduce the rotating speed for a certain airflow rate. The timing for replacement of the HEPA-filter in the FFU for effective filtration depends on the environmental conditions that it is used. If the condition of the area is clean, the time can be long, but if not, then short. Integration of a warning system that detects the clogging of the filter at a low cost can be another point of improvement of the FFU. Instead, a clock that shows the accumulated hours of use is integrated in the present FFU, as well as a warning red lamp that turns on at 1,000 hours.
Moreover, it is important for everyday operational purposes on a busy ward that a single operator can easily set up the hood quickly as required for individual patients, e.g., those newly diagnosed with influenza on a ward with high-risk (e.g., oncology) patients, where no other isolation facility is immediately available.

The medical staff is kept safe even while the hood is temporarily opened for medical procedures like checking blood pressure, pulse, inserting cannulas, taking blood, respiratory swabs, etc., by having the patient wear a respirator mask 10 minutes before the opening to clean the air inside. The patient wearing a mask has minimum risk of spreading the pathogen during the procedure.

Cleaning and disinfecting the inside and outside of the hoods after use and between patients should be easy to perform effectively and thoroughly, e.g., spraying with $70 \%$ ethanol then wiping down. Other chemical cleaners should be avoided if they have the potential to change the transparency of the curtains, such as high concentration of chlorine dioxide or ozone-based agents.

This lightweight, portable hood has proved to be a useful addition to temporary, ward-based infection control options to limit the transmission of airborne infectious agents. It may be suited to renal dialysis facilities and hospitals with not enough/no negative pressure facilities, or without enough number of individual patient isolation rooms, and could contribute to decrease the risk of nosocomial infections, not only in the case of seasonal influenza but also in cases of active tuberculosis and emerging respiratory contagious diseases, like SARS, MERS and COVID-19.

\section{Acknowledgments}

The authors greatly appreciate Dr. Julian W Tang for his 
helpful discussion, and editing the manuscript and Dr. Isolde Dapat for English language review.

Funding: Annual research subsidy from Sendai Medical Center, Sendai, Japan.

\section{Footnote}

Data Sharing Statement: Available at http://dx.doi. org/10.21037/jtd-20-1072

Conflicts of Interest: Both authors have completed the ICMJE uniform disclosure form (available at http://dx.doi. $\mathrm{org} / 10.21037 / \mathrm{jtd}-20-1072)$. SS is a retired ex-employee of Takasago Thermal Engineering Co. LTD. Japan worked as a technical expert. SS was retired three years ago and he has no right of the intellectual property on the Barrihood and does not get any reward from the company on it. HN has no conflicts of interest to declare.

Etbical Statement: The authors are accountable for all aspects of the work in ensuring that questions related to the accuracy or integrity of any part of the work are appropriately investigated and resolved. This study was approved by the ethics committee of Sendai National Hospital (approval No. 17-2). The study conformed to the provisions of the Declaration of Helsinki (as revised in 2013). Informed consent was waived due to the nature of the study.

Open Access Statement: This is an Open Access article distributed in accordance with the Creative Commons Attribution-NonCommercial-NoDerivs 4.0 International License (CC BY-NC-ND 4.0), which permits the noncommercial replication and distribution of the article with the strict proviso that no changes or edits are made and the original work is properly cited (including links to both the formal publication through the relevant DOI and the license). See: https://creativecommons.org/licenses/by-nc-nd/4.0/.

\section{References}

1. Wong BC, Lee N, Li Y, et al. Possible role of aerosol transmission in a hospital outbreak of influenza. Clin Infect Dis 2010;51:1176-83.

2. Wang D, Hu B, Hu C, et al. Clinical characteristics of
138 hospitalized patients with 2019 novel coronavirusinfected pneumonia in Wuhan, China. JAMA 2020;323:1061-9.

3. Assiri A, McGeer A, Perl TM, et al. Hospital outbreak of middle east respiratory syndrome coronavirus. $\mathrm{N}$ Engl J Med 2013;369:407-16.

4. Yan J, Grantham M, Pantelic JP, et al. Infectious virus in exhaled breath of symptomatic seasonal influenza cases from a college community. Proc Natl Acad Sci U S A 2018;115:1081-6.

5. Jochimsen EM, Fish L, Manning K, et al. Control of Vancomycin-Resistant Enterococci at a Community Hospital: Efficacy of Patient and Staff Cohorting. Infect Control Hosp Epidemiol 1999;20:106-9.

6. Miller SL, Clements N, Elliott SA, et al. Implementing a negative-pressure isolation ward for a surge in airborne infectious patients. Am J Infect Control 2017;45:652-9.

7. Milton DK, Fabian MP, Cowling BJ, et al. Influenza virus aerosols in human exhaled breath: particle size, culturability, and effect of surgical masks. PLoS Pathog 2013;9:e1003205.

8. Beggs CB, Kerr KG, Noakes CJ. The ventilation of multiple-bed hospital wards: review and analysis. Am J Infect Control 2008;36:250-9.

9. Ward M, Siegel JA, Corsi RL. The effectiveness of stand alone air cleaners for shelter-in-place. Indoor Air 2005;15:127-34.

10. Nishimura H, Sakata S, Kaga A. A New Methodology for Studying Dynamics of Aerosol Particles in Sneeze and Cough Using a Digital High-vision, Highspeed Video System and Vector Analyses. PLoS One 2013;8:e80244.

11. Hatagishi E, Okamoto M, Ohmiya S, et al. Establishment and clinical applications of a portable system for capturing influenza viruses released through coughing. PLoS One 2014;9:e103560.

12. Matrosovich M, Matrosovich T, Garten W et al. New lowviscosity overlay medium for viral plaque assays. Virol J 2006;3:63.

Cite this article as: Nishimura H, Sakata S. Development of a lightweight, 'on-bed', portable isolation hood to limit the spread of aerosolized influenza and other pathogens. J Thorac Dis 2020;12(7):3682-3687. doi: 10.21037/jtd-20-1072 